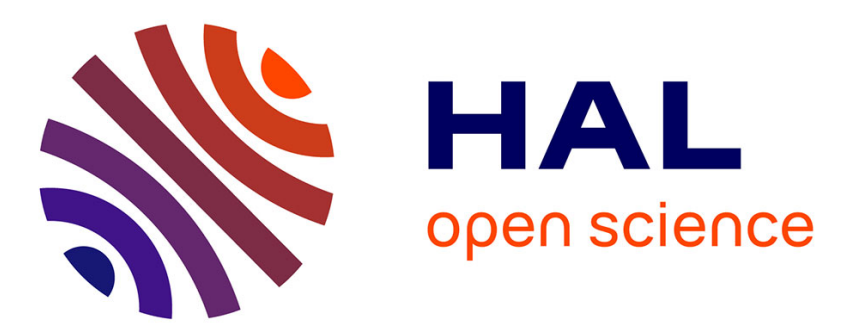

\title{
Effects of Rear Slant Angles on the Flow Characteristics of the Ahmed Body by IDDES Simulations
}

\author{
Emmanuel Guilmineau
}

\section{To cite this version:}

Emmanuel Guilmineau. Effects of Rear Slant Angles on the Flow Characteristics of the Ahmed Body by IDDES Simulations. SAE World Congress Experience, Apr 2018, Detroit, United States. 10.4271/2018-01-0720 . hal-02571303

\section{HAL Id: hal-02571303 https://hal.science/hal-02571303}

Submitted on 22 Jun 2020

HAL is a multi-disciplinary open access archive for the deposit and dissemination of scientific research documents, whether they are published or not. The documents may come from teaching and research institutions in France or abroad, or from public or private research centers.
L'archive ouverte pluridisciplinaire HAL, est destinée au dépôt et à la diffusion de documents scientifiques de niveau recherche, publiés ou non, émanant des établissements d'enseignement et de recherche français ou étrangers, des laboratoires publics ou privés. 


\title{
Effects of Rear Slant Angles on the Flow Characteristics of the Ahmed Body by IDDES Simulations
}

\author{
Emmanuel Guilmineau \\ Ecole Centrale Nantes, CNRS UMR 6598, BP 92101, 44321 Nantes, France
}

\begin{abstract}
The present study aims to investigate the effects of the several rear slant angles, $\varphi=25^{\circ}, 30^{\circ}, 32^{\circ}, 33^{\circ}$ and $35^{\circ}$, on the wake characteristics downstream of the Ahmed body because the angle of the rear window plays an important role in the flow characteristics. This work presents numerical simulations using ISIS-CFD flow solver which is developed by Centrale Nantes and CNRS. The turbulence model used is an hybrid RANS-LES model: the Improved Delayed Detached Eddy Simulation (IDDES). Detailed discussions of the flow features are provided using time-averaged streamlines, vorticity contours, turbulent kinetic energy contours and an isosurface of $\mathrm{l}_{2}$. Drag and lift coefficients are also presented. In the symmetry plane, three critical flow points, which correspond to foci of separation and saddle point in the wake of the Ahmed body, and the focus of separation over the slanted surface are presented. When the slant angle increases, these critical points move near the Ahmed body before moving away the model when the slant angle is higher than $33^{\circ}$. For the slant angle $\varphi=35^{\circ}$, a low drag configuration is predicted while for the other slant angles, a high drag flow configuration is predicted where two C-pillars vortex are present. These vortices move away the model when the slant angle increases.
\end{abstract}

\section{Introduction}

Current environmental and economic issues lead automotive manufacturers to search for innovative solutions to reduce the fuel consumption of vehicles. The reduction of aerodynamic drag of vehicles is one solution to save fuel. For ground vehicles with a motion at $100 \mathrm{~km} / \mathrm{h}$, the air resistance represents more than $60 \%$ of the total drag [1]. Even after decades of investigations, drag reduction considerations are still an objective of manufacturers. To achieve this goal, passive systems, as spoilers or fins, or fluidic systems, as blowing, suction or synthetic jet, can be used. However, the implementation of such solution requires a very strong knowledge of the physical phenomena in the near wake flow around the vehicle. Descriptions of flow features and their interactions are important for understanding the aerodynamic properties of a vehicle body. The size of the separation zone, and thus the drag coefficient, depends on the position of the flow separation. Consequently, for the successful design of future cars, a strong understanding about the wake flow features and its relation with the vehicle geometry is necessary.

The so-called Ahmed body [2] is perhaps the most studied simplified car model which is a three dimensional bluff-body for which one of the first representation of the flow around an automotive flow is given where a view of the time-averaged flow around the rear part is presented. As the front of this model is designed to avoid separation, Page 1 of 11 the forces are determined by the flow structures created on the afterbody which are unsteady and three dimensional. Following the slant angle, three major structures are observed: a separation bubble on the base of the model, strong longitudinal vortices or C-pillars and a recirculation bubble on the rear window [2].

Nowadays, the Ahmed body is considered as a reference model for both experimental and numerical investigations although this model fails to reproduce important parts of the flow, as the flow in the wheelhouses in combination with rotating wheels. Numerous experimental investigations used this model, see [3-7]. Most of these experimental studies have investigated the flow characteristics by time-averaged flow informations. Last few years, some experiments give informations about the unsteady characteristics of the flow [810]. The first numerical simulation were carried out by Han [11]. Since, there have been a lot of numerical studies which give informations about time-averaged flow characteristics but also instantaneous features [12-19]. However, these numerical simulations were carried out for the slant angles $\varphi=25^{\circ}$ or $35^{\circ}$ which correspond to two states of the flow. However, the slant angle at which the change of state occurs is not known.

The objective of this paper is to investigate the effects of several rear slant angles, $\varphi$, on the time-averaged flow characteristics on the rear window and in the wake of the Ahmed model. This paper is a numerical investigation using the flow solver ISIS-CFD with an hybrid RANS-LES turbulence model. This paper is organized as follows. The test-case is presented in the first section. The following section briefly describes the numerics. The numerical set-up is presented included information about the computational domain and the meshes. Then, the results are presented. Finally, main conclusions of this work are given.

\section{Generic Ground Vehicle Body}

The Ahmed body [2] used in this paper is shown in Figure 1. This model is a generic car geometry which consists of three parts: a fore body with the edges rounded, a middle section which is a box of rectangular section with sharp edges and a sharp slanted rear upper surface for which the slant angle, $\varphi$, is adjustable. This slant angle is the main variable in the experimental work of Ahmed et al. [2]. The pressure drag represents most of the drag of the body and mainly generates at the rear end. In the experimental work of Ahmed et al. [2], the maximum drag is found for the slant angle $\varphi=30^{\circ}$. Above this angle, the flow is fully detached over the rear window due to the low pressure gradient between the roof and the slant. Below this angle, the flow is separated and characterized by strong side edge vortices and a separation bubble on the slant surface. The 
reattachment of this bubble depends on the slant angle. Lienhart et al. [3] performed further experiments for the same body for two representative slant angles, $\varphi=25^{\circ}$ and $\varphi=35^{\circ}$ for which LDA measurements of the mean velocity and turbulence statistics are obtained.

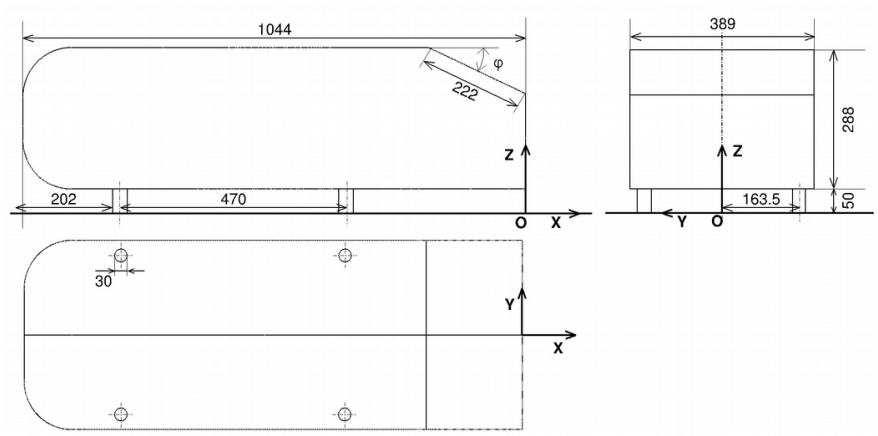

Figure 1. Side, rear and top view of the Ahmed body. Distance are in mm.

The length of the model is $\mathrm{L}=1044 \mathrm{~m}$, the width $\mathrm{W}=389 \mathrm{~m}$, the height is $H=288 \mathrm{~mm}$. The ground clearance is $\mathrm{G}=50 \mathrm{~mm}$ and the diameter of the four feet is $\phi=30 \mathrm{~mm}$. The reference axis $(\mathrm{x}, \mathrm{y}, \mathrm{z})$ is linked to the model. The origin of these axis is related to the point $\mathrm{O}$ located on the floor of the wind tunnel at the base of the model and in the symmetry plane of the model, see Figure 1. Another reference axis $\left(\mathrm{x}_{\mathrm{w}}, \mathrm{y}_{\mathrm{w}}, \mathrm{z}_{\mathrm{w}}\right)$ is linked to the rear window. The Reynolds number, $\operatorname{Re}=7.6810^{5}$, is based on the height of the model and the incoming velocity $\mathrm{U}_{\infty}=40 \mathrm{~m} / \mathrm{s}$. This Reynolds number is the same as the one used in the experiments of Lienhart et al. [3].

For the Ahmed body wake, the estimation length scales for the Kolmogorov scale is $\eta \approx 1.2 \mathrm{Re}^{-0.75}$, and for the Taylor scale $\lambda_{\mathrm{T}} \approx$ $5.5 \mathrm{Re}^{0.5}$. This estimations are proposed by Howard and Pourquie [20]. The length scale $l_{0}$ of the largest anisotropic structures containing energy may be estimated by $l_{0} \approx \eta \mathrm{Re}^{3 / 4}$. Then, the inertial range lies from $l_{\mathrm{EI}} \approx 1_{0} / 6$, between the anisotropic large eddies and the anisotropic small eddies, to $l_{\mathrm{DI}} \approx 60 \eta$, between the inertial and dissipative range [18]. The viscous boundary sublayer at the end of the vehicle is $\eta_{\mathrm{nw}} \approx 6.71 \mathrm{Re}^{-0.9}$, which equals to 1 in wall units. All these lengths are given in Table 1.

Table 1. Characteristic length scales evaluated for the Ahmed body flow at Re $=7.6510^{5}$.

\begin{tabular}{|l|c|c|c|c|c|c|}
\hline & $\mathrm{l}_{0}$ & $\mathrm{l}_{\mathrm{EI}}$ & $\lambda_{\mathrm{T}}$ & $\mathrm{l}_{\mathrm{DI}}$ & $\eta$ & $\eta_{\mathrm{nw}}$ \\
\hline Dimensionless & 1.2 & 0.02 & 0.0063 & 0.0028 & $4.6310^{-5}$ & $3.410^{-5}$ \\
\hline In mm & 345.6 & 57.6 & 1.807 & 0.799 & 0.013 & 0.0098 \\
\hline
\end{tabular}

\section{Numerical Method}

The ISIS-CFD flow solver, developed by the Ecole Centrale de Nantes and CNRS, uses an incompressible unsteady Reynoldsaveraged Navier-Stokes (URANS) method. The solver is based on a finite volume method to build the spatial discretization of the transport equations. The unstructured discretization is face-based, which means that cells with an arbitrary number of arbitrarily shaped faces are accepted. A second order backward difference scheme is used to discretize time. The solver can simulate both steady and unsteady flows. In the case of turbulent flows, additional transport equations for the variables in the turbulence model are added.
The solver features sophisticated turbulence models: apart from the classical two-equation k- $\varepsilon$ and $\mathrm{k}-\omega$ models, the anisotropic twoequation Explicit Algebraic Reynolds Stress Model (EARSM), as well as Reynolds Stress Transport Models, are available [21,22]. All these turbulence models are RANS models. A Detached Eddy Simulation (DES) approach, based on k- $\omega$ model, has been introduced [23]. Recently, some modifications of this formulation proposed by Griskevich et al. [24] include recalibrated empirical constants in the shielding function and a simplification of the original Spalart-Allmaras-based formulation. This new model is called Improved Delayed Detached Eddy Simulation (IDDES).

All flow variables are stored at the geometric center of arbitrary shaped cells. Volume and surface integrals are evaluated with secondorder accurate approximations. The method is face-based, which means that the fluxes in the cells are computed face by face. Thus, the cells with an arbitrary number of arbitrarily shaped faces are accepted. Numerical fluxes are reconstructed on the mesh faces by linear extrapolation of the integrand from the neighboring cell centers. A centered scheme is used for the diffusion terms, whereas for the convective fluxes, a blended scheme with 95\% central differences and 5\% upwind differences is used. A central differencing scheme may become unstable for high values of the cell Reynolds number, and a upwind differencing scheme tends to introduce numerical diffusion. This is particularly problematic with LES. The low value of the upwind scheme is to prevent instabilities. These values are also used by LES in automotive flow [25].

The velocity field is obtained from the momentum conservation equations and the pressure field is extracted from the mass conservation constraint or continuity equation, transformed into a pressure-equation. The pressure equation is obtained by the Rhie and Chow interpolation technique [26]. The momentum and pressure equations are solved in an segregated manner as in the SIMPLE coupling procedure [27].

\section{Numerical Simulation Set-Up}

For all slant angles, the computational domain starts $7.25 \mathrm{H}$ in front of the model and extends to $18.125 \mathrm{H}$ behind the model. The width of the domain is $6.493 \mathrm{H}$ and its height is $4.861 \mathrm{H}$. These dimensions are recommended for the ERCOFTAC workshop on Refined Turbulence Modelling [28], and the cross section of the channel is identical to the open test section of the wind tunnel used in the experiments [3]. For all simulations, the feet are taken into account. The mesh is generated using Hexpress ${ }^{\mathrm{TM}}$, an automatic unstructured mesh generator. This software generates meshes containing only hexahedrals. For the car model and the floor, a no-slip boundary condition is used and the wall normal resolution is set to $0.0007 \mathrm{~mm}$ which is below the $\eta_{\mathrm{nw}}$ length, see Table 1. A first refinement box is added around the after body, in which the sizes of the cell are $\Delta \mathrm{x}=\Delta \mathrm{y}=\Delta \mathrm{z}=1.8 \mathrm{~mm}$. This box covers the slant surface and the base and extends until $0,1 \mathrm{~m}$ in the wake of the model. A second box including all the Ahmed body and extending until $0,5 \mathrm{~m}$ in the wake of the model is also added. In this box, the cell sizes are $\Delta x=\Delta y=\Delta z=3.6 \mathrm{~mm}$. From these cell sizes, it can be seen that the grid has its smallest cells of the same order as the Taylor scale. Thus, according to Howard and Pourquie [20], the grid is appropriate for the precision required for LES and for DES simulations. The cell size in the first box is similar to the Taylor scale. A view of the mesh is given in Figure 2.

Guilmineau et al. [23] investigated with a DES approach the flow around the Ahmed body with the slant angle $\varphi=25^{\circ}$. In this paper, three meshes, containing 7.5, 12.3 and 23.6 million nodes, were used 
to a mesh convergence, and the conclusion was that the variation of the drag coefficient between the medium and the fine meshes is less than $1 \%$. So, the fine mesh is used in this paper. Table 2 gives informations about the mesh for each slant angle. The difference of the number of cells and thus faces to describe the model is due to the fact that the mesh is anisotropic on the surface for the slant angles $25^{\circ}$ and $35^{\circ}$ while for the other slant angle the mesh is isotropic.

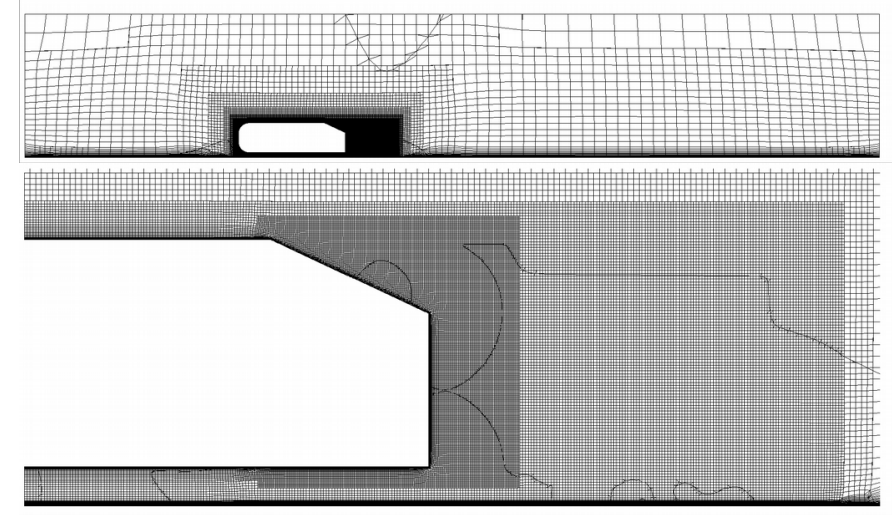

Figure 2. View of the mesh in the symmetry plane for the $25^{\circ}$ slant angle.

General view (upper), zoom at the after body (lower).

Table 2. Informations about the meshes versus the slant angle.

\begin{tabular}{|c|c|c|}
\hline Slant angle & Number of cells & $\begin{array}{c}\text { Number of faces on } \\
\text { the model }\end{array}$ \\
\hline $25^{\circ}$ & $23.110^{6}$ & 384,090 \\
\hline $30^{\circ}$ & $30.010^{6}$ & 523,712 \\
\hline $32^{\circ}$ & $28.210^{6}$ & 524,742 \\
\hline $33^{\circ}$ & $26.910^{6}$ & 523,354 \\
\hline $35^{\circ}$ & $22.210^{6}$ & 379,358 \\
\hline
\end{tabular}

The influence of the turbulence model plays an important role for the prediction of the flow around the Ahmed body, and especially for the slant angle $\varphi=25^{\circ}$. Guilmineau et al. [29] showed that the use of the Improved Delayed Detached Eddy Simulation (IDDES), which is an hybrid RANS-LES turbulence model, gives a good prediction of the flow and a good agreement with experimental data, even for the slant angle $\varphi=25^{\circ}$. Therefore, this turbulence model is used in this paper. With the hybrid RANS-LES models, the flow is by nature unsteady and the time step is $\Delta t=2.510^{-4} \mathrm{~s}$. The averaging time, $\mathrm{tU}_{\infty} / \mathrm{H}$, in the simulation is approximately 150 .

\section{Results}

Figure 3 presents the vortex structures around the Ahmed body by using a iso-surface of the non dimensional invariant $\lambda_{2}$. For the slant angles $\varphi=25^{\circ}, 30^{\circ}, 32^{\circ}$ and $33^{\circ}$, the wake is highly three-

dimensional with partial separation on the slant surface along with longitudinal vortices coming from the slant side edges or C-pillars. The size of this separation on the slant surface increases as the slant angle increases as well as the size of the C-pillars. The flow topology is very similar for the slant angles $\varphi=32^{\circ}$ and $\varphi=33^{\circ}$. For the slant angle $\varphi=35^{\circ}$, the C-pillar vortices are weaker and then the flow separates fully on the slant. The slant angles $25^{\circ}, 30^{\circ}, 32^{\circ}$ and $33^{\circ}$ are called high drag flow

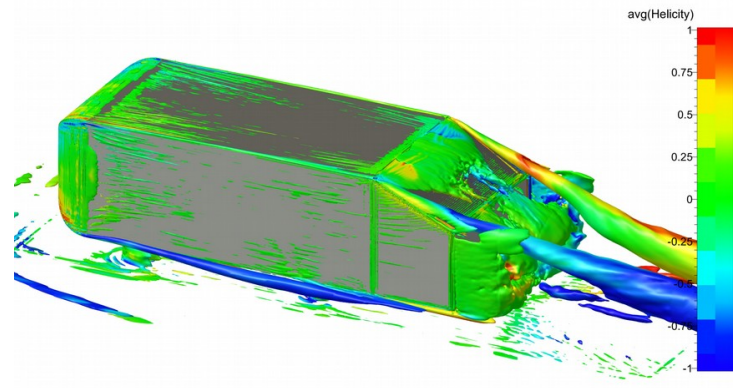

(a) $\varphi=25$ deg.

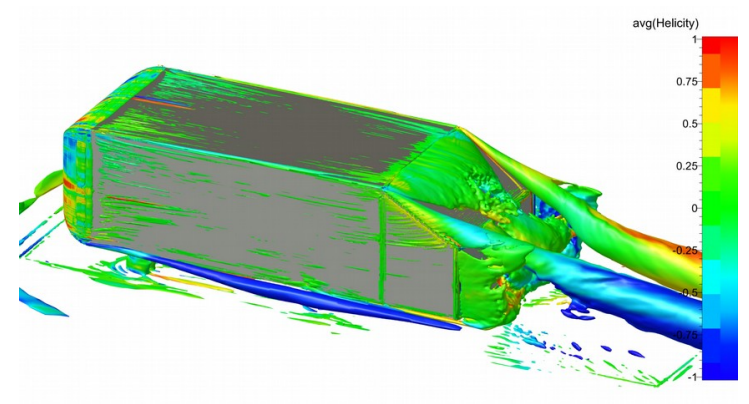

(b) $\varphi=30 \mathrm{deg}$.

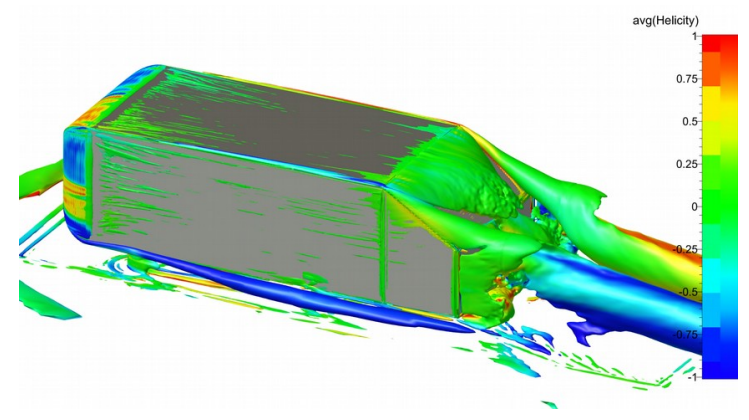

(c) $\varphi=32$ deg.

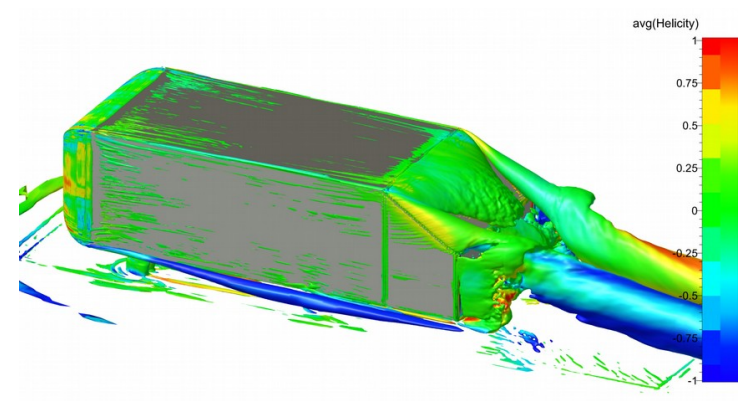

(d) $\varphi=33$ deg.

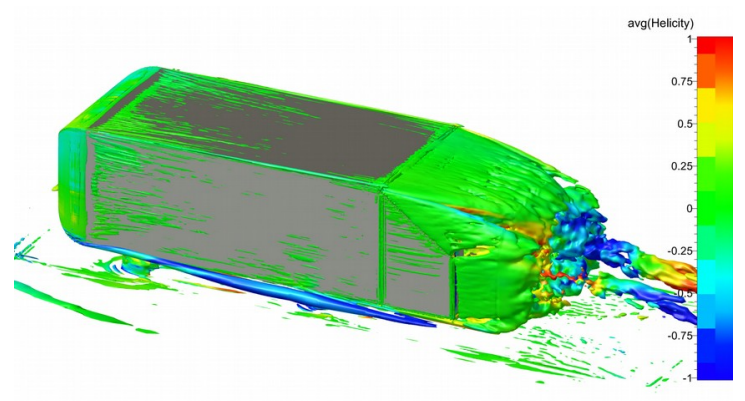

(e) $\varphi=35$ deg.

Figure 3. Vortex structures visualized by the iso-surface of the nondimensional time-averaged $\lambda_{2}\left(\lambda_{2}=-0.76\right)$ versus the slant angle. 
configuration, according to the notations used by Ahmed et al. [2] while the slant angle $35^{\circ}$ is the low drag flow configuration. For all slant angles, longitudinal vortices are formed around the lateral lower edge. These vortices are also observed by Krajnovic and Davidson [30] which used a LES approach. In their study, the core of the vortex keeps the initial position in the y-z plane along the body. It is not the case in this study; the core of the vortex deviates from the body and goes down toward the ground.

The velocity in the C-pillars decreases as the slant angle increases, as shown in Figure 4 which presents the streamwise velocity at the end of the model, $\mathrm{x} / \mathrm{H}=0$. The view shows a zoom of the left corner of the model. It is clear that the size of the model increases as the slant angle increases but also the velocity in the core of the vortex decreases. As the velocity in the C-pillars decreases, those become weaker and the fluid on the rear window coming from the roof is not constrained. Thus, the recirculation bubble on the rear window can increases as the slant angle increases.

The drag and lift coefficients are computed as $C_{D}=F_{X} /\left(0.5 \rho U_{\infty}{ }^{2} A\right)$ and $\mathrm{C}_{\mathrm{L}}=\mathrm{F}_{\mathrm{Z}} /\left(0.5 \rho \mathrm{U}_{\infty}{ }^{2} \mathrm{~A}\right)$ where $\mathrm{F}_{\mathrm{X}}$ and $\mathrm{F}_{\mathrm{Z}}$ are drag and lift forces, respectively, and $\mathrm{A}$ is the frontal area. These coefficients are presented in Table 3 versus the slant angle. When the slant angle increases until $\varphi=33^{\circ}$, the drag coefficient increases as well as the lift coefficient. After this slant angle, the drag coefficient decreases and the lift coefficient drops and becomes negative. This explains the name given by Ahmed et al. [2] for the flow configurations: high drag flow configuration and low drag flow configuration.

Table 3. Drag and lift coefficients versus the slant angle.

\begin{tabular}{|c|c|c|c|c|c|}
\hline$\varphi$ [deg.] & 25 & 30 & 32 & 33 & 35 \\
\hline $\mathrm{C}_{\mathrm{D}}$ & 0.380 & 0.431 & 0.480 & 0.483 & 0.355 \\
\hline $\mathrm{C}_{\mathrm{L}}$ & 0.330 & 0.419 & 0.430 & 0.456 & -0.014 \\
\hline
\end{tabular}

Table 4 presents the pressure drag coefficient with a similar force decomposition of Ahmed et al. [2] where $C_{S}$ is the pressure force on the rear windows and $C_{B}$ the the pressure force on the base of the model. $C_{D, P}$ represents the pressure drag coefficient obtained from the front, the rear slanted and the base surfaces. Breaking down the pressure drag with the help of $C_{B}$ and $C_{S}$ gives the relative contributions presented in Table 3 . The force on the rear window, $\mathrm{C}_{\mathrm{s}}$, dominates the pressure force for each slant angle. The maximum contribution is obtained for the slant angle $\varphi=30^{\circ}$. The ratios between the pressure drag on the rear window or on the base and the pressure drag are similar to those obtained experimentally. For the high flow configuration, the pressure drag on the rear window increases as the slanted surface angle increases until $\varphi=32^{\circ}$ while the pressure drag on the base decreases until $\varphi=32^{\circ}$ and then increases after this slant angle.

Figure 5 presents the friction lines on the Ahmed body. Common to all these figures is the separation region at the beginning of the top, at the lateral sides and at the bottom of the body. Some experimental studies [5, 31] and numerical results [16, 18] have recorded the recirculation on the front part of the body. Nevertheless, most studies do not provide data for the upstream flow and only focus on the rear window and the near wake of the model.

For the high drag flow configuration, the streamlines issued from the lateral side of the body separate along the lateral edges of the rear

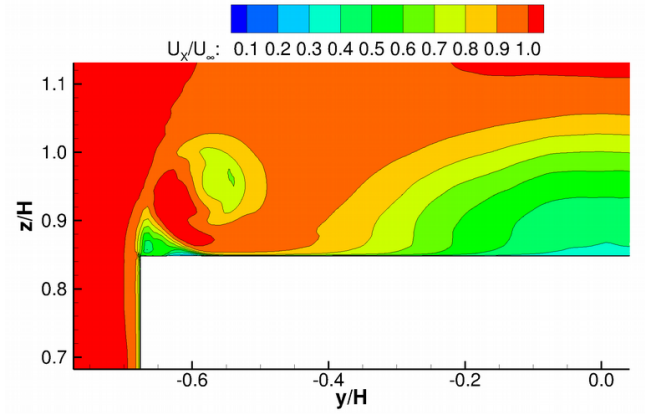

(a) $\varphi=25$ deg.

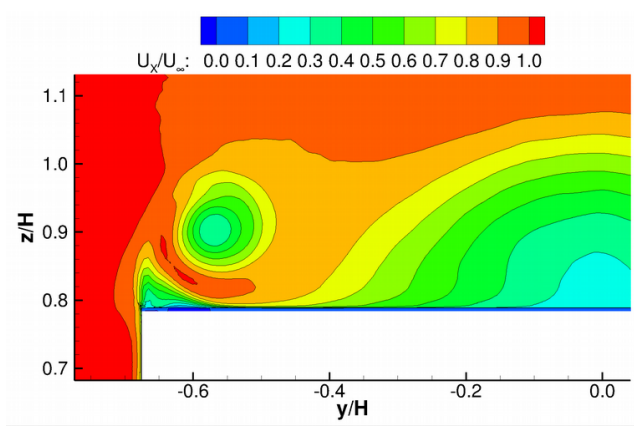

(b) $\varphi=30 \mathrm{deg}$

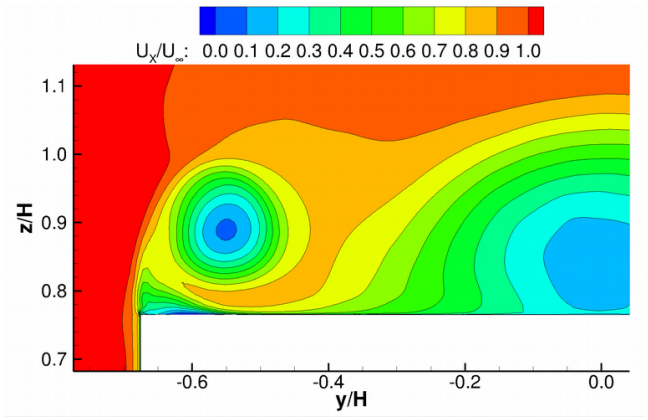

(c) $\varphi=32$ deg.

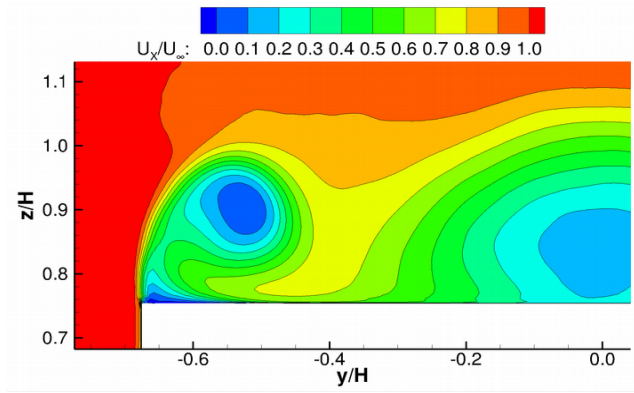

(d) $j=33$ deg.

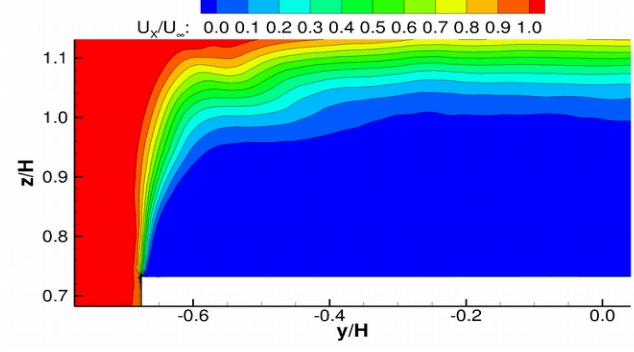

(d) $\varphi=35$ deg.

Figure 4. Time-averaged streamwise velocity at $\mathrm{x} / \mathrm{H}=0$ versus the slant angle. 


\begin{tabular}{|c|c|c|c|c|c|}
\hline $\begin{array}{c}\varphi \\
\text { [deg.] }\end{array}$ & Model & $\begin{array}{c}\mathrm{C}_{\mathrm{B}} \\
{[-]}\end{array}$ & $\begin{array}{c}\mathrm{C}_{\mathrm{B}} / \mathrm{C}_{\mathrm{D}, \mathrm{P}} \\
{[\%]}\end{array}$ & $\begin{array}{c}\mathrm{C}_{\mathrm{S}} \\
{[-]}\end{array}$ & $\begin{array}{c}\mathrm{C}_{\mathrm{S}} / \mathrm{C}_{\mathrm{D}, \mathrm{P}} \\
{[\%]}\end{array}$ \\
\hline 25 & IDDES & 0.126 & 39.0 & 0.188 & 58.2 \\
& Ahmed et al [2] & 0.086 & 35.1 & 0.141 & 57.6 \\
\hline 30 & IDDES & 0.112 & 30.3 & 0.251 & 67.9 \\
& Ahmed et al [2] & 0.090 & 28.0 & 0.213 & 66.4 \\
\hline 32 & IDDES & 0.117 & 27.9 & 0.290 & 69.2 \\
\hline 33 & IDDES & 0.120 & 28.4 & 0.291 & 68.8 \\
\hline 35 & IDDES & 0.139 & 46.6 & 0.153 & 51.2 \\
& Ahmed et al [2] & 0.089 & 44.3 & 0.097 & 48.3 \\
\hline
\end{tabular}

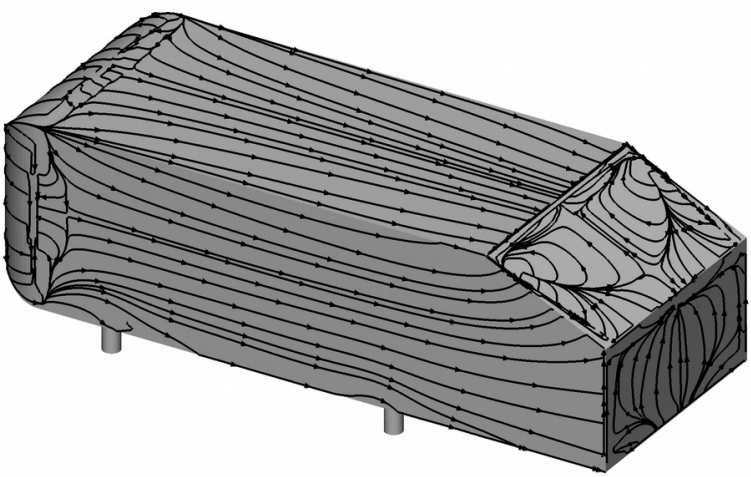

(a) $\varphi=25$ deg.

slanted surface, roll up into the longitudinal vortex and reattach themselves on the rear window. This clearly visible in Figure 6 which presents the time-averaged streamlines around the after-body of the Ahmed with a slant angle $\varphi=25^{\circ}$. Then, a portion of the fluid moves toward the side edge and separates again along a separation line. For the high drag flow configuration, see Figure 5(a), 5(b) or 5(c), the flow in the middle part of the slant surface separates at the upstream edge. The presence of C-pillar vortices prevents this separated flow to extend in the spanwise direction. This recirculation bubble over the rear window reattaches on the slant. For the slant angle $\varphi=25^{\circ}$, the reattachment point is located at $77 \%$ of the slant length while in experiments [32], at the same Reynolds number, this point is located at $72 \%$ of the slant length. For the slant angle $\varphi=30^{\circ}$, this point is located at $87 \%$ of the slant length while for the slant angle $\varphi=32^{\circ}$, the reattachment point is located at $94 \%$ of the slant length. The friction lines indicate the existence of secondary counter-rotating longitudinal vortices along the lateral edge as observed by Krajnovic and Davidson [30] and visible in Figure 7 where the massive vortex corresponds to the C-pillar and the secondary vortices those located close to the side edge of the rear window.

For the low drag flow configuration, $\varphi=35^{\circ}$, the shear layer developed on the roof of the model separates near the upper edge of the rear window, as shown in Figure 8. The streamlines issued from the lateral side of the model do not roll up into a longitudinal vortex and so the C-pillar vortex is not present.

In Figure 9, the time-averaged streamline patterns of the flow around the Ahmed body with several slant angles are presented in the symmetry plane $y / H=0$. These figures show changes in the flow features by providing 2D velocity field. For the high drag flow configuration, a recirculation bubble is predicted on the slanted surface. This separation is generated at the edge between the roof of the model and the rear window. When the slant angle increases, the size of the bubble increases and the reattachment point moves downstream. For the low drag flow configuration, $\varphi=35^{\circ}$ see Figure 9(d), the bubble is now located at the end of the rear window. The size of the separation in the wake becomes bigger than those observed for the high drag flow configurations.

Figure 10 presents a comparison of the critical point positions, defined in the previous figure. Figure 10(a) shows the position of the separation on the rear window in the slanted surface reference axis while Figure 10(b) presents the position of the foci of the separation and the saddle point in the wake of the Ahmed body. For the

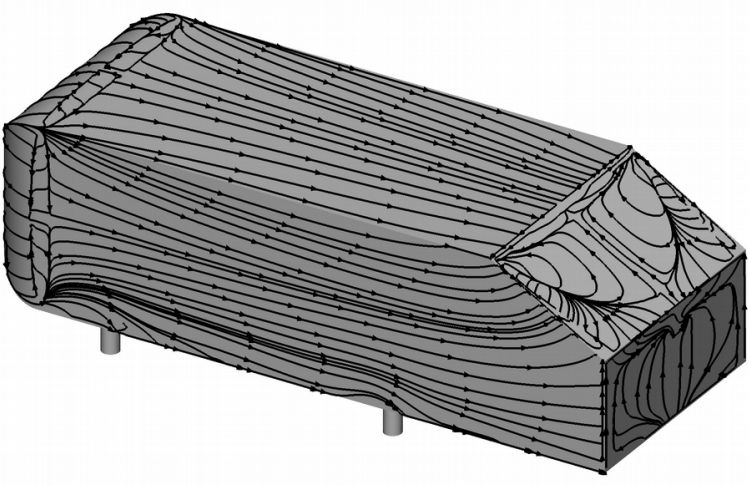

(b) $\varphi=30 \mathrm{deg}$

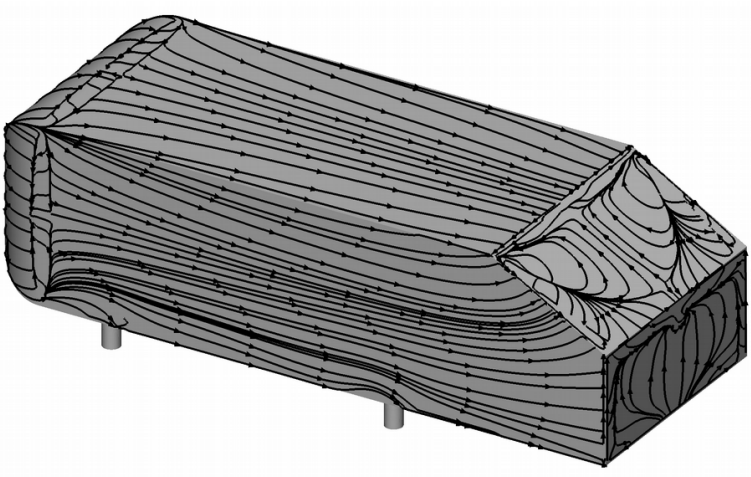

(c) $\varphi=32 \mathrm{deg}$.

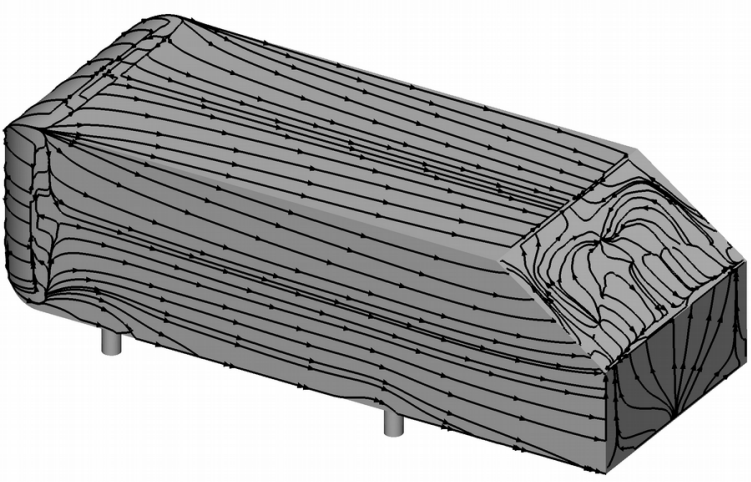

(d) $\varphi=35$ deg. 
Figure 5. Time-averaged friction lines on the Ahmed body versus the slant angle.
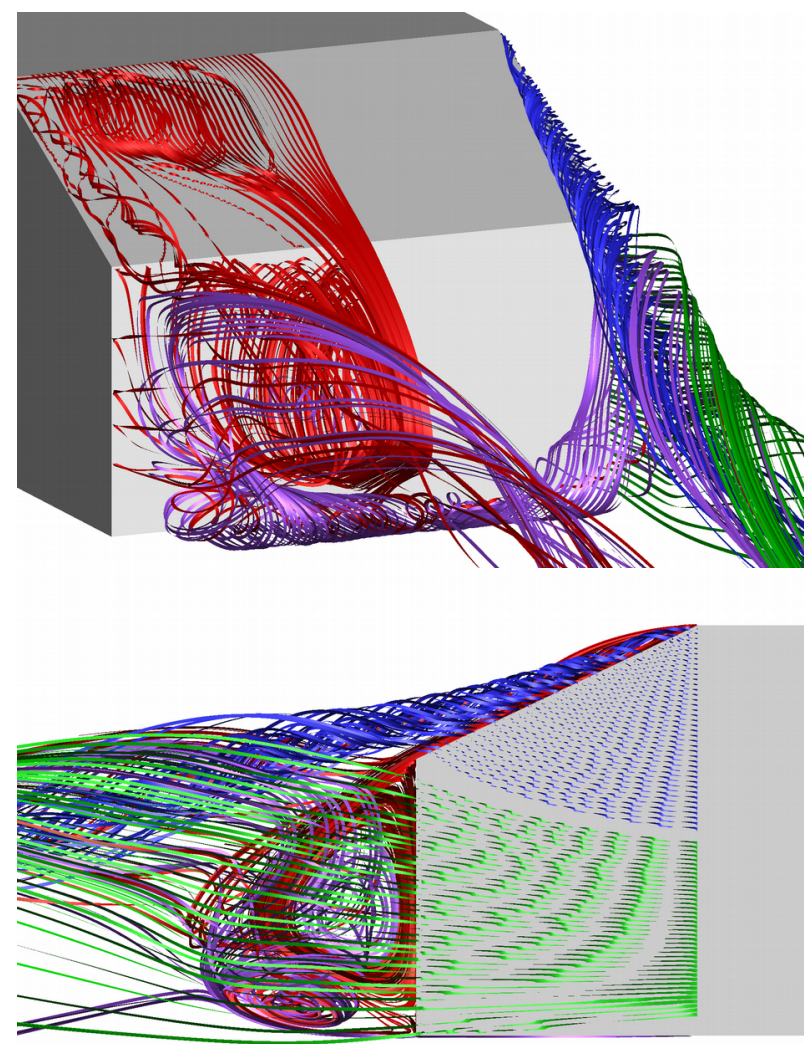

Figure 6. Time-averaged stream-ribbons from the edge between the roof and the rear slant surface (purple), between the underbody and the the base (red), from the upper part(blue) and the lower part of the side (green) of the model for the slant angle $\varphi=25$ deg. Back view (upper), side view (lower).
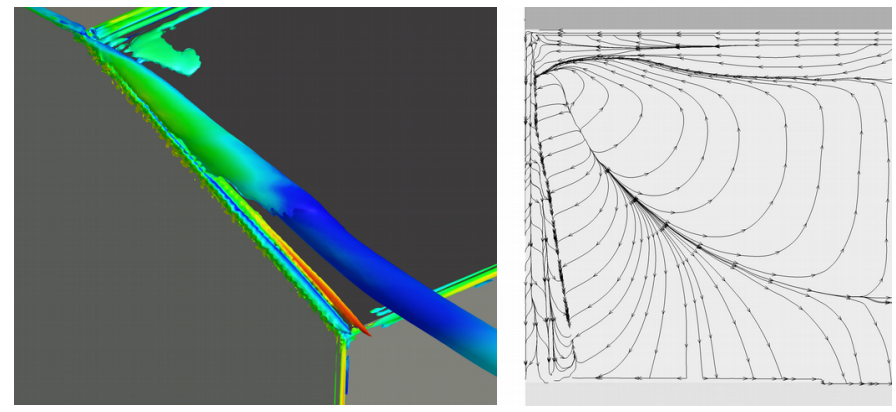

Figure 7. Vortex structures around the side edge of the rear window for the slant angle $\varphi=25 \mathrm{deg}$. Visualization of the iso-surface of the non-dimensional $\lambda_{2}\left(\lambda_{2}=-100\right)$ (left side), Friction lines on the rear window (right side).

separation on the rear window, the position of the focus F3 is approximately the same for the high drag flow configuration. The switch to the low drag configuration, $\varphi=35^{\circ}$, leads to a major change in the location of the focus F3. This point moves to the end of the rear window and moves away from the slanted surface. For the wake, we observe three main results related to the change in the slant angles. Firstly, the change in the slant angles from $33^{\circ}$ to $35^{\circ}$ has much more effect than the change in the slant angles from $25^{\circ}$ to $33^{\circ}$. This remark is in opposite direction than the experimental observations of Tunay et al. [10] which used the $1 / 4$ scaled Ahmed body. In their experiments, for the slant angle $\varphi=30^{\circ}$, they observed the low drag flow configuration as defined by Ahmed et al. [2] while Page 6 of 11 the high drag flow configuration is observed in the present paper for the same slant angle. The second observation is that all critical points
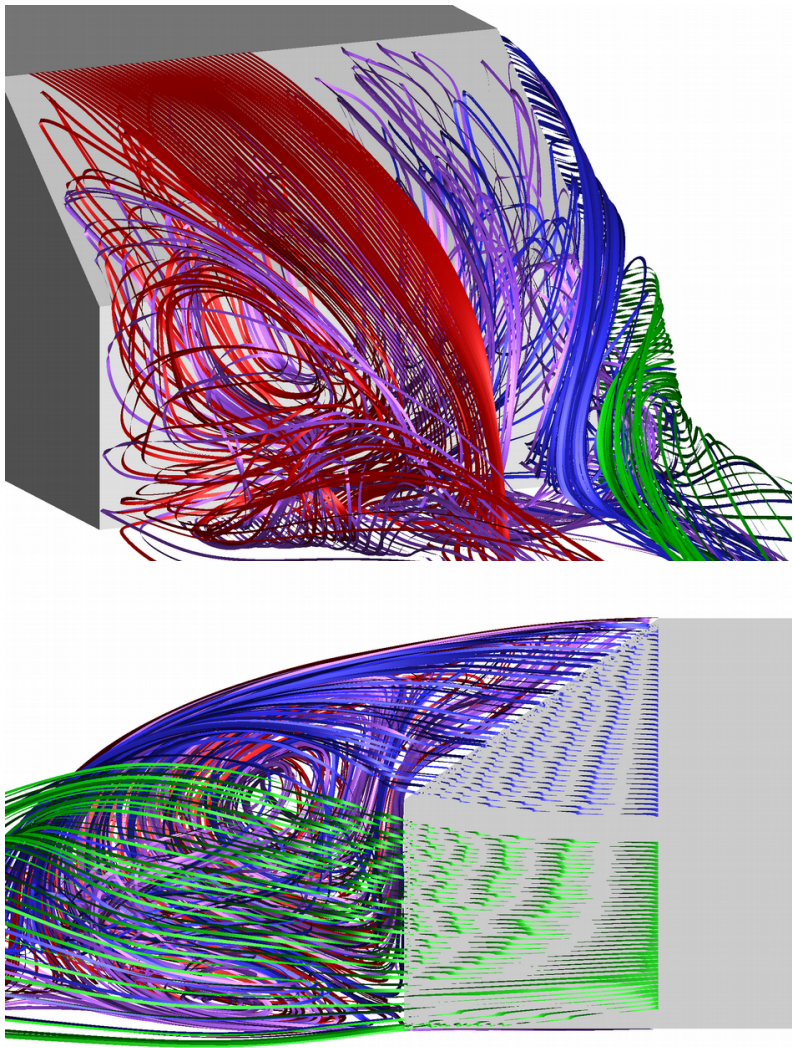

Figure 8. Time-averaged stream-ribbons from the edge between the roof and the rear slant surface (purple), between the underbody and the the base (red), from the upper part(blue) and the lower part of the side (green) of the model for the slant angle $\varphi=35$ deg. Back view (upper), side view (lower).

move towards the Ahmed body for changing slant angle from $25^{\circ}$ to $33^{\circ}$ while, for the low drag flow configuration, all critical points move away from the model. Thirdly, the modification of the rear slant angle from $33^{\circ}$ to $35^{\circ}$ has more effects on the vertical position of the focus point $\mathrm{F} 1$ than on the vertical position of the focus F2 and the saddle point S2. However this change of the slant angle has more effects on the horizontal position of the focus point F2 and the saddle point S2 than the focus point F1.

Figure 11 presents the non dimensional vorticity contours, $\omega_{\mathrm{Y}}$, in the symmetry plane. The vorticity contours on the rear window for the high drag flow configuration is nearly attached on the slanted surface while for the low drag flow configuration, $\varphi=35^{\circ}$, vorticity contours are completely detached. The region with the maximum vorticity around the rear window increases as the slant angle increases until $\varphi$ $=32^{\circ}$. At the same time, the maximum of vorticity in the wake of the model comes closer to the base of the Ahmed body. In the wake region from the underbody flow, the region size of negative vorticity decreases also until the slant angle $\varphi=32^{\circ}$. After this slant angle, the size of this region increases.

Figure 12 compares the iso-contours of the non dimensional streamwise vorticity in the transversal plane at $\mathrm{x} / \mathrm{H}=0.278$. For the high drag flow configuration, $\varphi=25^{\circ}, 30^{\circ}$ or 32 , the wake is very similar. Two strong longitudinal vortices or C-pillars are visible. These vortices emanate from the lateral side of the slanted surface, 
grow and become fully developed in the wake of the model. Two other concentrations are observed in the middle of the rear window but their levels are weaker than the C-pillars. Behind the base of the

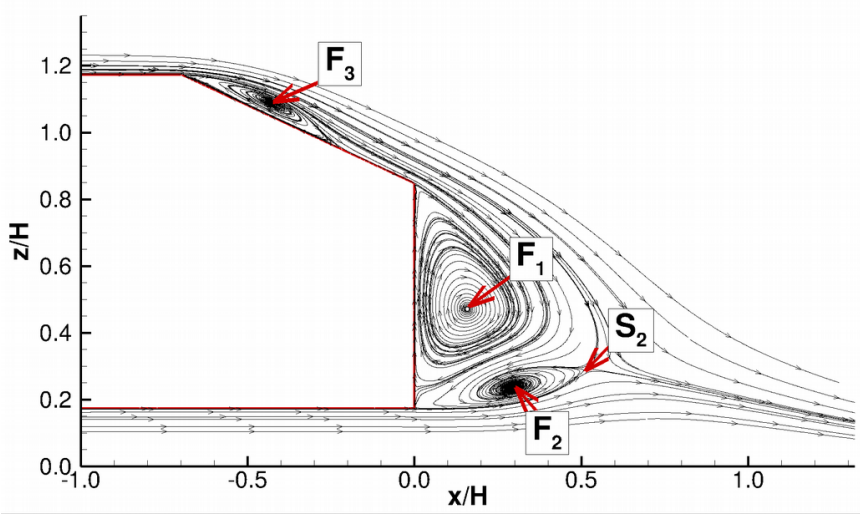

(a) $\varphi=25$ deg.

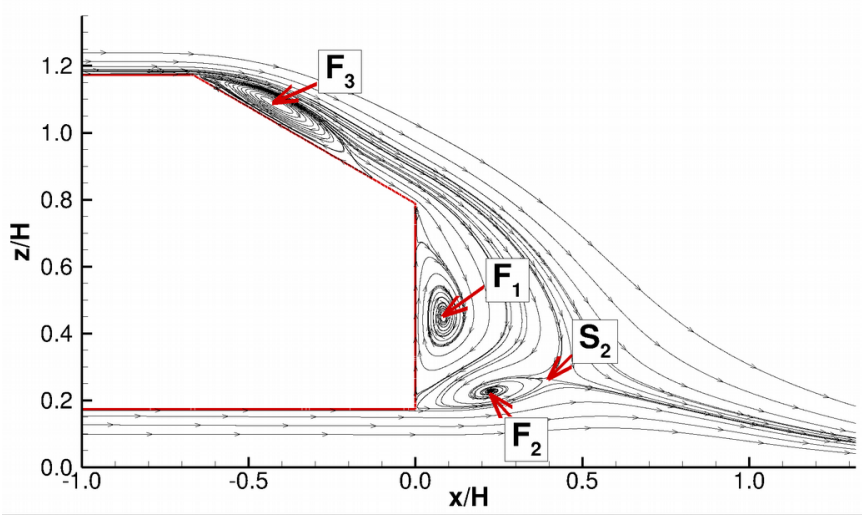

(b) $\varphi=30$ deg.

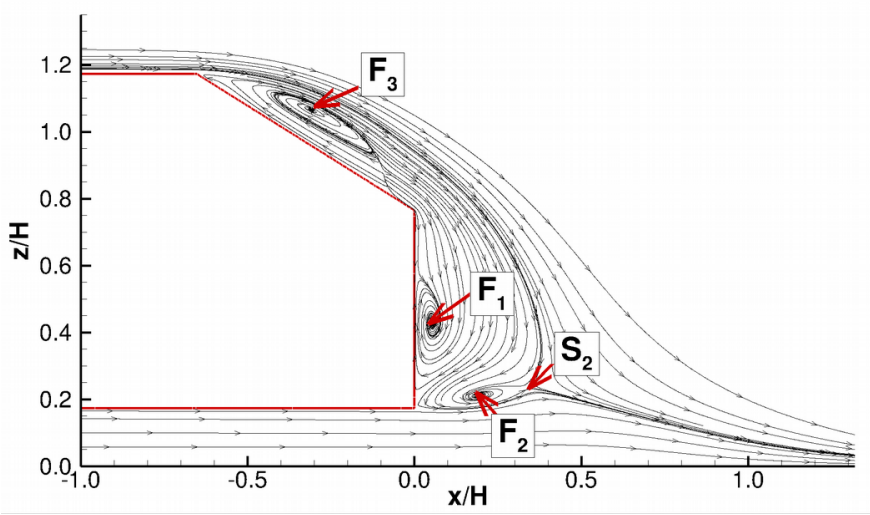

(c) $\varphi=32$ deg.

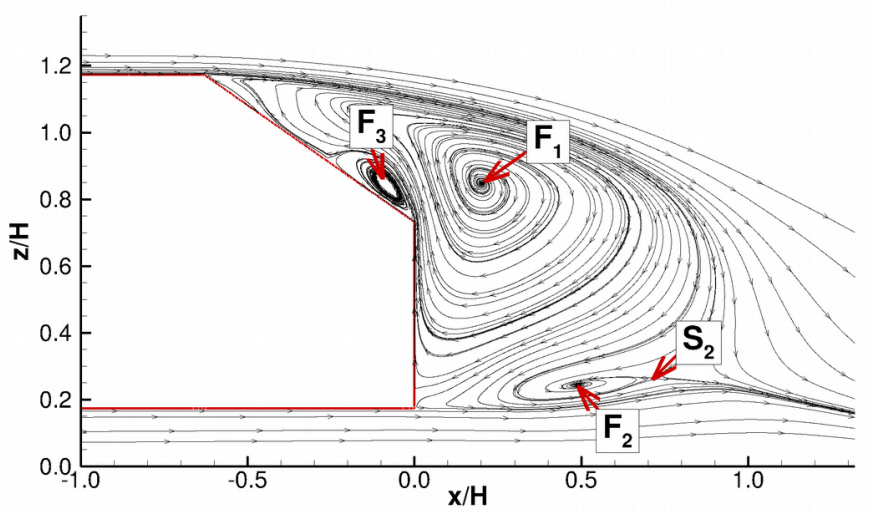

Page 7 of 11 (d) $\varphi=35$ deg.

Figure 9. Patterns of time-averaged streamlines in the symmetry plane, $\mathrm{y}=0$.

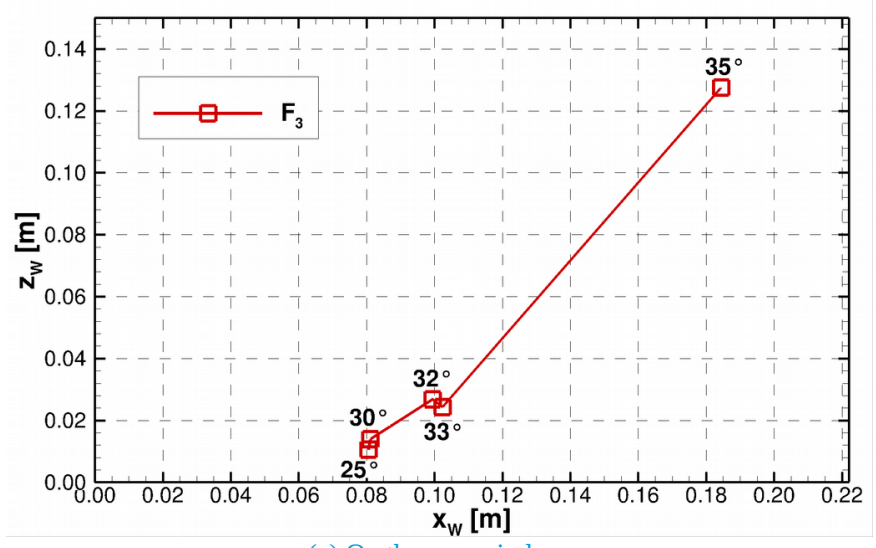

(a) On the rear window.

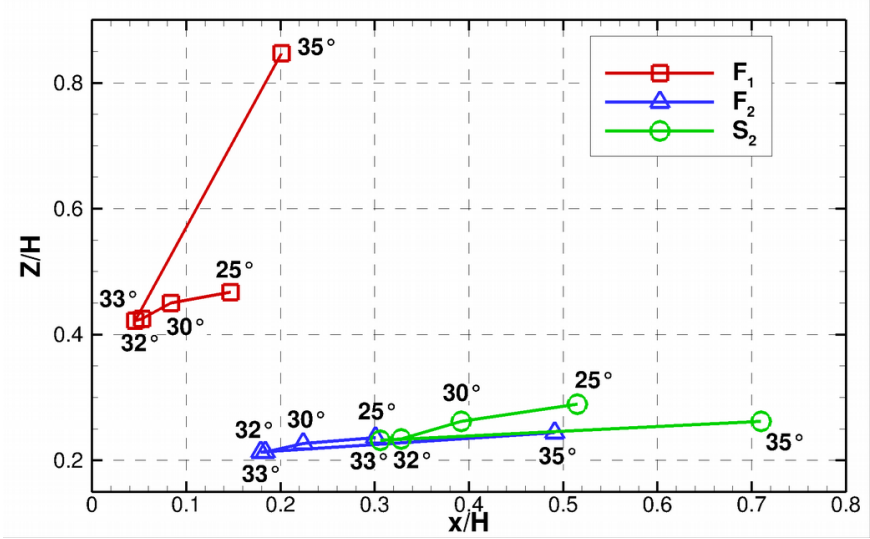

(b) In the wake of the model.

Figure 10. Locations of the critical points (foci and saddle points).

model, there are many vorticity concentrations. Near the lower corners of the model, one additional pair of counter-rotating longitudinal vortices is visible but their maximum value is very small compared to the values of the C-pillars. These vortices were observed numerically by Krajnovic and Davidson [30], but also experimentally by Strachan et al. [33]. In both cases, the four cylindrical feet are not taken into account and for Strachan et al. [33], the inclusion of these struts suppresses the formation of these vortices because most previous measurements failed to capture these vortices. Recently, Wang et al. [9] showed experimentally the presence of these vortices even with a model with their four feet as in the present study. For the low drag flow configuration, $\varphi=35^{\circ}$, the C-pillar vortices are not present and some vorticity concentrations are observed below the upper edge of the rear window. These concentrations are due to the flow separation and are convected by the downwash flow. The maximum concentration of these vortices exhibit a reduction in size compared to those obtained for the high drag flow configuration. Their maximum vorticity concentration has also diminished. One pair of vortices between the floor and the underbody of the model is present. For the high drag flow configuration, these vortices are not present due to the downwash flow which is more stronger .

Figure 13 presents the time-averaged vertical velocity in the plane $\mathrm{x} / \mathrm{H}=0.278$ for several slant angles. For the high drag flow configuration, the negative contours covers the rear window, they are just constrained by positive concentrations due to the C-pillars. On the base of the model, the velocity is more and more negative. This is 
due to the fact that the vortex moves towards the model as the slant angle increases. For the low drag configuration, because of the the

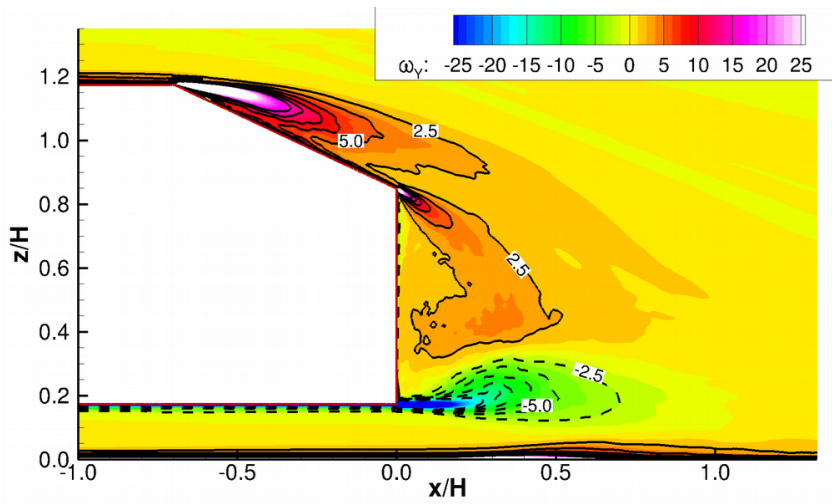

(a) $\varphi=25$ deg.

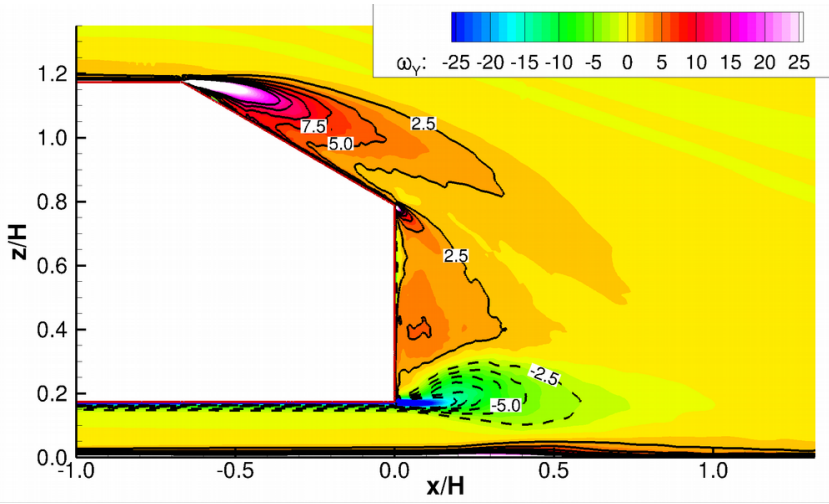

(b) $\varphi=30 \mathrm{deg}$.

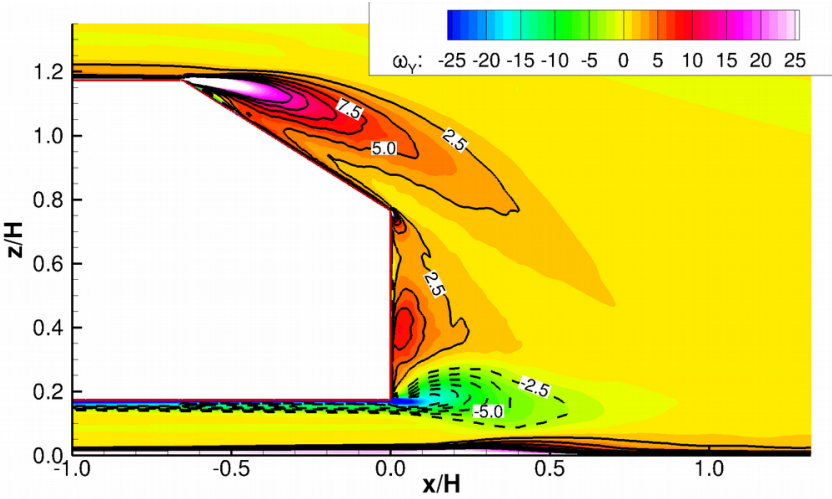

(c) $\varphi=32 \mathrm{deg}$.

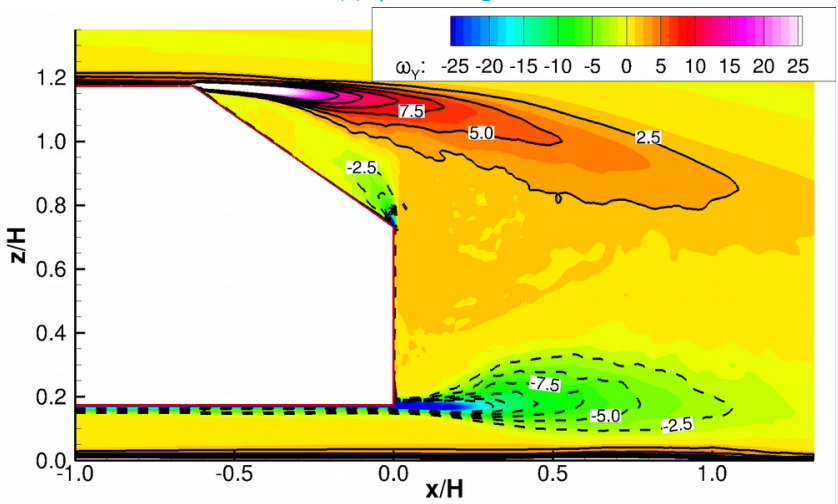

(d) $\varphi=35$ deg.
Figure 11. Patterns of time-averaged non dimensional vorticity contours in the symmetry plane.

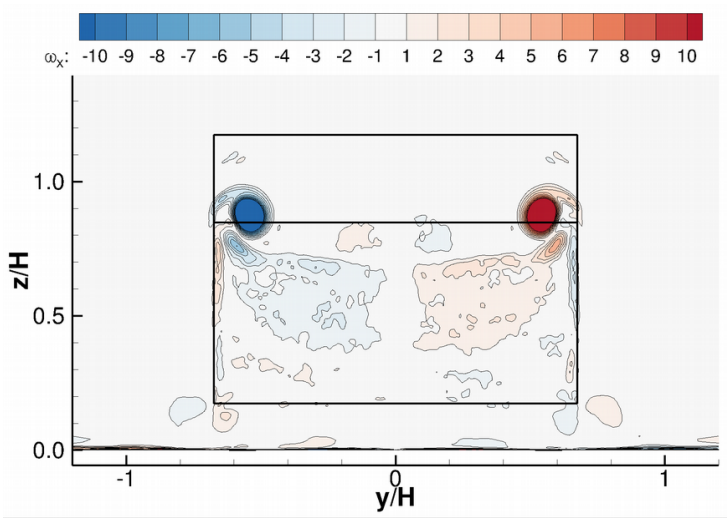

(a) $\varphi=25 \mathrm{deg}$.

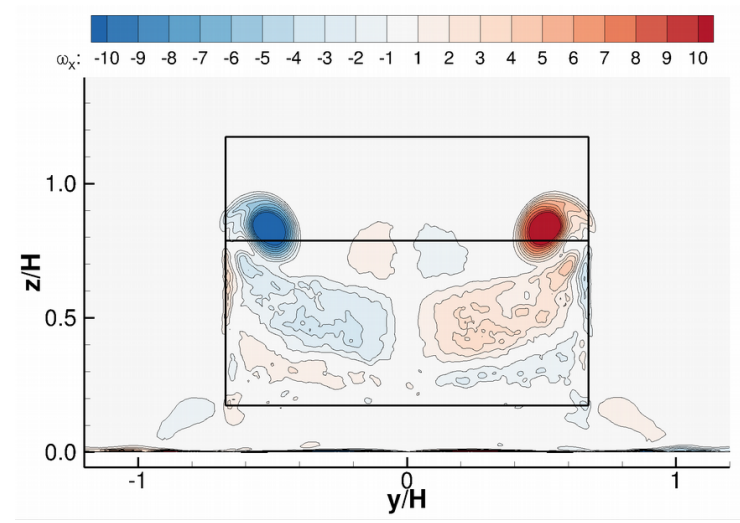

(b) $\varphi=30 \mathrm{deg}$.

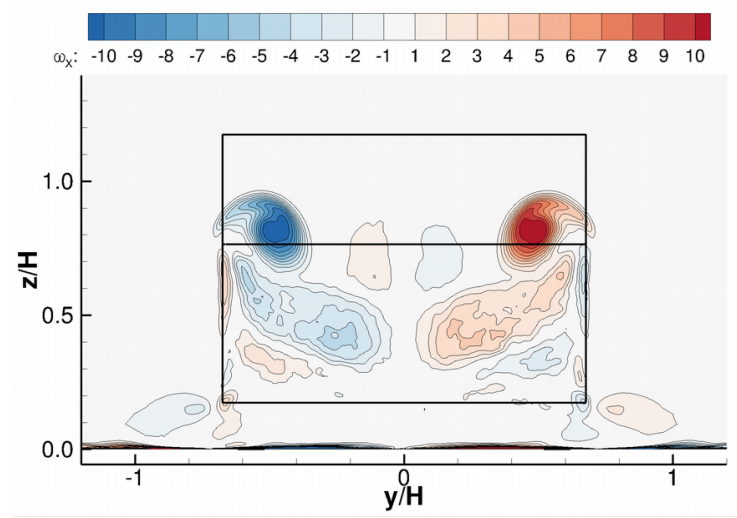

(c) $\varphi=32$ deg.

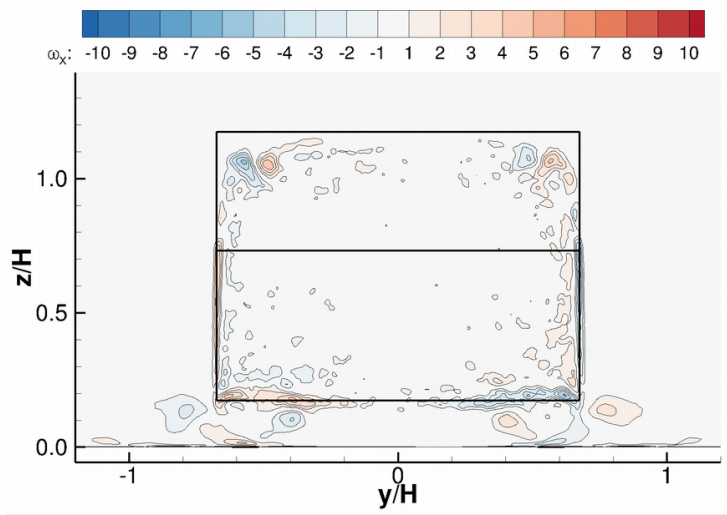

Page 8 of 11 
(d) $\varphi=35$ deg.

Figure 12. Patterns of time-averaged vorticity contours in the plane $\mathrm{x} / \mathrm{H}=$ 0.278 .

separation bubble on the slant surface, the downwash flow is very less intense. By contrast with the high low drag configuration, a region with negative contours in the lower part of of the base of model is predicted.

The non-dimensional turbulent kinetic energy (TKE) distributions are presented in Figure 14. As TKE is directly associated to the flow dynamics, this quantity is a measurement of the turbulence mixing For the high drag flow configuration, the same patterns of TKE is obtained while for the low drag flow configuration, the patterns is different. The major difference is that, for the high drag flow configuration, over the rear window, TKE increases in the flow direction starting from the upper edge of the rear window until the position of the bubble reattachment point. After this point, TKE decreases. As the slant angle increases, the size of the region of maximum TKE on the slanted surface increases. For the low drag flow configuration, TKE is low over the rear window. For all slant angles, a maximum of TKE is observed at the lower shear layer. As the slant angle increases, the maximum value of TKE in this region increases until $\varphi=33^{\circ}$ and is near the base of the Ahmed body. For the slant angle $\varphi=35^{\circ}$, this region moves away and the maximum value is lower.

\section{Conclusions}

This present study aims at investigating the effects of the rear slant angles, $\varphi=25^{\circ}, 30^{\circ}, 32^{\circ}, 33^{\circ}$ and $35^{\circ}$, on the wake flow characteristics downstream of the Ahmed body because the flow separation downstream of the Ahmed body contributes most of its drag. In the present study, a numerical investigation with the flow solver ISIS-CFD and an hybrid RANS-LES turbulence model, the socalled IDDES, was carried out.

Similar to the notations used by Ahmed et al. [2], the slant angles $\varphi=$ $25^{\circ}, 30^{\circ}, 32^{\circ}$ and $33^{\circ}$ are high drag flow configurations while the slant angle $\varphi=35^{\circ}$ is a low drag flow configuration. With the high drag flow configuration, strong side, edge vortices, or C-pillars, are generated as well as a recirculation bubble on the rear window, and a separation emanating from the base of the model. On the one hand, these vortices makes approximately the same angle with the side edges of the rear window, but on the other hand, these vortices moves away from the rear window when the slant angle increases. For a low drag flow configuration, C-pillars do not exist and a large recirculation in the wake exists.

The angle of the rear window have significant effects on the characteristics of the wake flow. A variation of the slant angle from $\varphi$ $=25^{\circ}$ to $\varphi=33^{\circ}$ induces that the separations become closer to model when the slant angle increases. After the slant angle $\varphi=33^{\circ}$, the separations move away from the model.

With the aim of reducing vehicles fuel consumption, one way is to reduce aerodynamic drag, and especially the pressure drag, using flow control techniques. Hence, the prediction of the wake is essential in order to compare the effects of the control. And a change in the geometry, like the slant angle for the Ahmed body, must be correctly predicted by the numerical simulation. This study shows that the numerical simulations with the hybrid RANS-LES model, called IDDES, correctly predict the flow topology. And thus this turbulence model can be used for the future simulations with synthetic jets in order to reduce the drag.

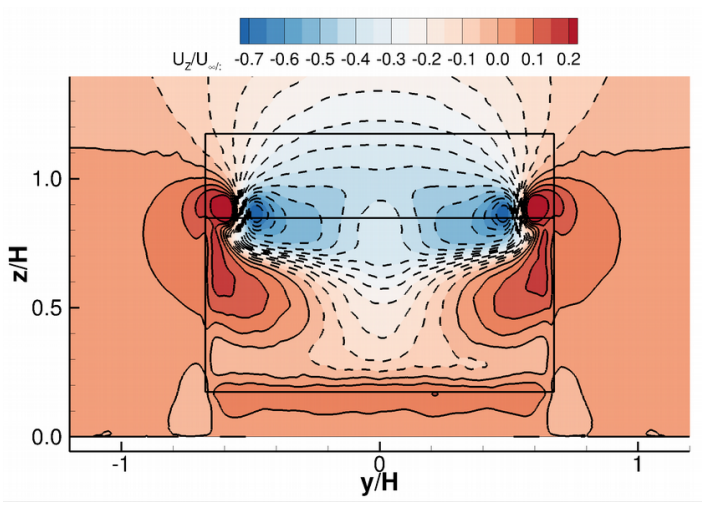

(a) $\varphi=25$ deg.

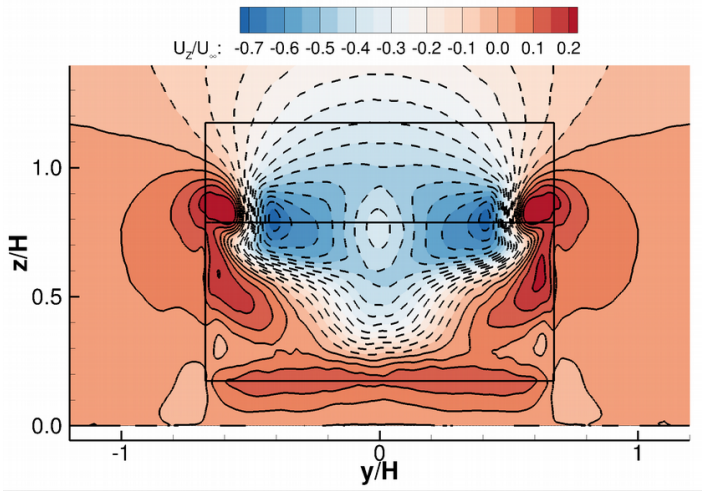

(b) $\varphi=30 \mathrm{deg}$.

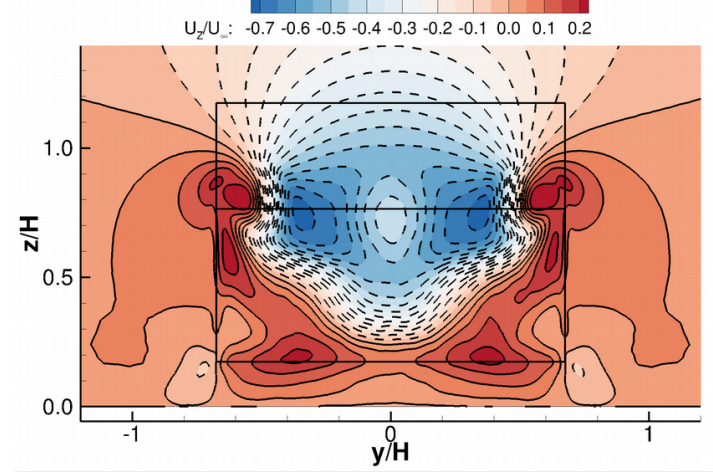

(c) $\varphi=32$ deg.

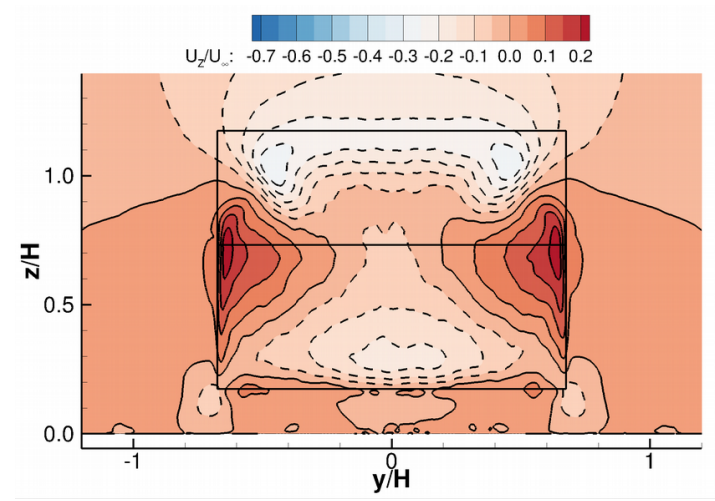


Figure 13. Patterns of time-averaged vertical velocity in the plane $\mathrm{x} / \mathrm{H}=$ 0.278 .

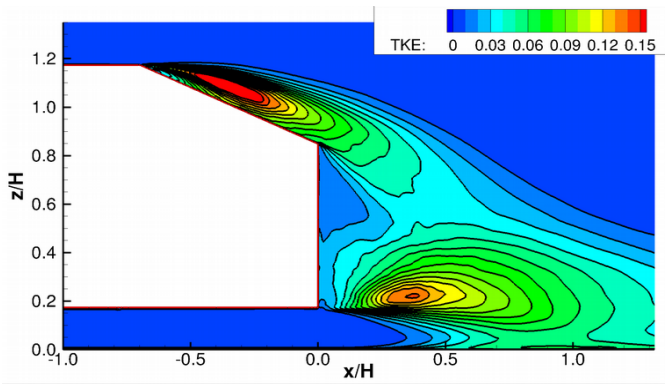

(a) $\varphi=25$ deg.

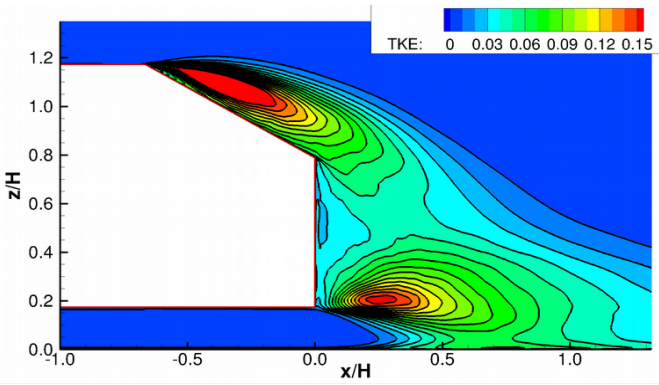

(b) $\varphi=30 \mathrm{deg}$.

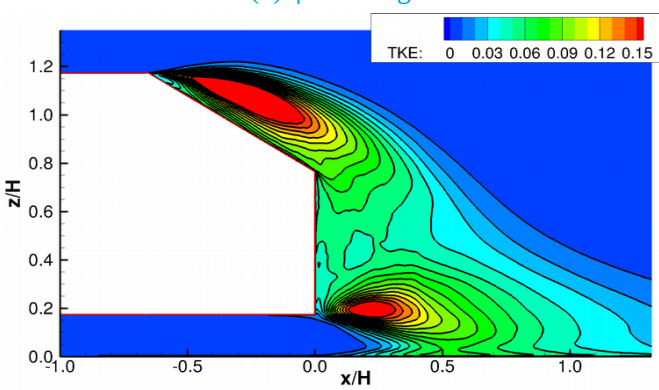

(c) $\varphi=32$ deg.

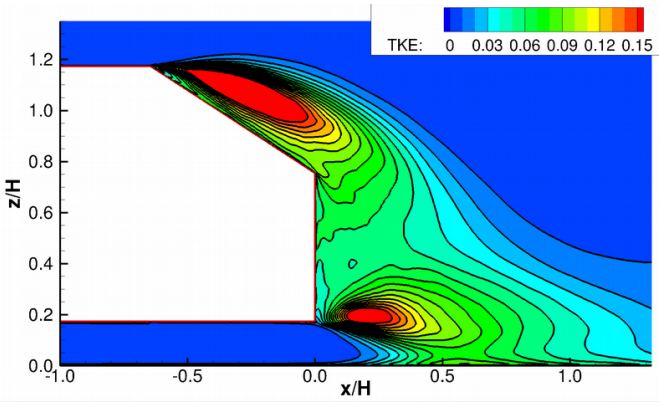

(d) $\varphi=33$ deg.

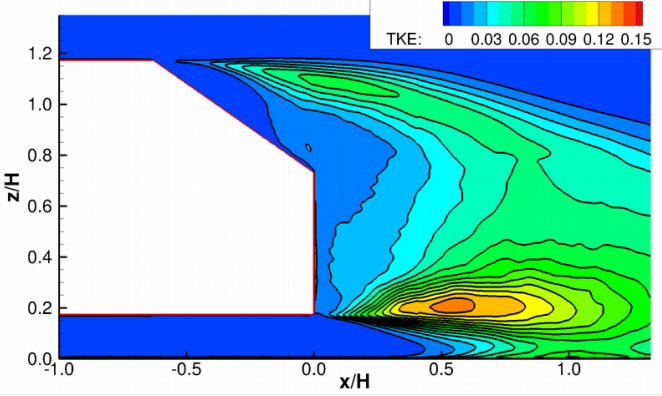

Figure 14. Patterns of time-averaged non-dimensional turbulent kinetic energy in the symmetry plane.

\section{References}

1. Hucho, W.H., “Aerodynamics of Road Vehicles”, SAE International, 1998, ISBN: 978-0-7506-1267-8.

2. Ahmed, S.R., Ramm, G. and Faltin, G., "Some Salient Features of the Time-Averaged Ground Vehicle Wake”, SAE Technical Paper 840300, 1984, doi:10.4271/840300.

3. Lienhart H, and Becker S., "Flow and Turbulence Structure in the Wake of a Simplified Car Model”, SAE Technical Paper 2003-01-0656, 2003, doi:.10.4271/2003-01-0656.

4. Sims-Williams, D.B., "Self-excited Aerodynamic Unsteadiness Associated with Passenger Cars", PhD Thesis, University of Durham, 2001.

5. Spohn, A. and Gilliéron, P., "Flow Separations Generated by a Simplified Geometry of an Automotive Vehicle”, IUTAM Symposium on Unsteady Separated Flows. Toulouse, France, 2002.

6. Vino, G., Watkins S, Mousley P, Watmuff, J. and Prasad, S. "Flow Structures in the Near-Wake of the Ahmed Body", Journal of Fluids and Structures, 20:673-695, 2005, doi:10.1016/j.jfluidstructs.2005.03.006.

7. Conan, B. Anthoine, J. and Planquart, P., "Experimental Aerodynamic Study of a Car-Type Bluff Body", Experiments in Fluids, 50(5):1273-1284, 2011, https://doi.org/10.1007/s00348010-0992-z.

8. Thacker, A., Aubrun, S., Leroy, A. and Devinant, P. "Experimental Characterization of Flow Unsteadiness in the Centreline Plane of an Ahmed Body Rear Slant”, Experiments in Fluids, 54(3):1479, 2013, doi:10.1007/s00348-013-1479-5.

9. Wang, X.W, Zhou, Y., Pin, Y.F. and Chan T.L., "Turbulent near Wake of an Ahmed Vehicle Model”, Experiments in Fluids, 54(4):1490, 2013, doi:10.1007/s00348-013-1490-x.

10. Tunay, T., Sahin, B. and Ozbolat, V., "Effects of Rear Slant Angles on the Flow Characteristics of Ahmed Body", Experimental Thermal and Fluid Science, 57:165-176, 2014, doi:10.1016/j.expthermflusci.2014.04.016.

11. Han, T., "Computational Analysis of Three-Dimensional Turbulent Flow around a Bluff Body in Ground Proximity", AIAA Journal, 27(9):1213-1219, 1989, doi:10.2514/3.10248.

12. Gilliéron, P. and Chometon, F., "Modelling of Stationary ThreeDimensional Separated Air Flows around an Ahmed Reference Model”, EASIM Proceedings, Vortex Flows and Related Numerical Methods III, 7:173-182, 1999.

13. Kapadia, S., Roy, S., Vallero, M., Wurtzler, K. and Forsythe, J., "Detached-Eddy Simulation over a Reference Ahmed Car Model”, In: Friedrich R., Geurts B.J., Métais O. (Eds) Direct and Large-Eddy Simulation V, ERCOFTAC Series, vol. 9, pp. 481-488, 2004.

14. Hinterberger, C., Garcia-Villalba, M. and Rodi, W., "Large Eddy Simulation of Flow around the Ahmed Body", In: McCallen R., Browand F., Ross J. (Eds) the Aerodynamics of Heavy Vehicles: Trucks, Buses, and Trains. In Applied and Computational Mechanics, vol. 19, pp. 77-87, 2004.

15. Fares, E. "'Unsteady Flow Simulation of the Ahmed Reference Body using a Lattice Boltzmann Approach”, Computers and Fluids, 35(8-9):940-950, 2006, doi:10.1016/j.compfluid.2005.04.011.

16. Krajnovic, S. and Davidson, L., "Flow Around a Simplified Car, Part 1: Large Eddy Simulation”, Journal of Fluids Engineering, 127(5):907-918, 2005, doi:10.1115/1.1989371.

Page 10 of 11 
17. Guilmineau, E., "Computational Study of Flow Around a Simplified Car Body", Journal of Wind Engineering and Industrial Aerodynamics, 96(6-7):1207-1217, 2008, doi:10.1016/j.jweia.2007.06.041.

18. Minguez, M., Pasquetti, R. and Serre, E., "High-Order Large Eddy Simulation of Flow over the 'Ahmed Body' Car Model”, Physics of Fluids, 20(9):095101, 2008, doi:10.1063/1.2952595.

19. Ashton, N. and Revell, A., "Key Kactors in the Use of DDES for the Flow Around a Simplified Car”, International Journal of Heat and Fluid Flow, 54:236-249, 2015, doi:10.1016/j.ijheatfluidflow.2015.06.002.

20. Howard, R.J.A. and Pourquie, "Large Eddy Simulation of an Ahmed Reference Model”, Journal of Turbulence, 3(1):12, 2002, doi:10.1088/1468-5248/3/1/012.

21. Duvigneau, R., Visonneau, M. and Deng, G.B., "On the Role Played by Turbulence Closures in Hull Ship Optimization at Model and Full Scale”, Journal of Marine Science and Technology, 8:11-25, 2003, doi:10.1007/s10773-003-0153-8.

22. Deng, G.B. and Visonneau, M., "Comparison of Explicit Algebraic Stress Models and Second-Order Turbulence Closures for Steady Flow Around Ships”, In $7^{\text {th }}$ International Conference on Numerical Ship Hydrodynamics, Nantes, France, 1999.

23. Guilmineau, E., Deng, G.B. and Wackers, J., "Numerical Simulation with a DES Approach for Automotive Flows”, Journal of Fluids and Structures, 27(5-6):807-816, 2011, doi:10.1016/j.jfluidstructs.2011.03.010.

24. Gritskevich, M.S., Garbaruk, A.V., J. Schütze, J. and Menter, F.R., "Development of DDES and IDDES Formulations for the k- $\omega$ Shear Stress Transport Model”, Flow, Turbulence and Combustion, 88(3):431-449, 2012, doi:10.1007/s10494-0119378-4.

25. Krajnovic, S. and Sarmast, S., "Numerical Investigation of the Influence of Side Winds on a Simplified Car at Various Yaw Angles”, In $3^{\text {rd }}$ Joint US-European Fluids Engineering Summer Meeting, Montreal, Canada, 2010, FEDSM-ICNMM201030687.

26. Rhie, C.M. and Chow, W.L., "A Numerical Study of the Turbulent Flow past an Isolated Aerofoil with Trailing Edge Separation”, AIAA Journal, 17(11):1525-1532, 1983, doi:10.2514/3.8284.

27. Issa, R.I., "Solution of the Implicitly Discretised Fluid Flow Equations by Operator-Splitting”, Journal of Computational Physics, 62(1):40-65, 1986, doi:10.1016/0021-9991(86)90099-9.
28. Manceau, R. and Bonnet, J.P. (Eds) In $10^{\text {th }}$ Joint ERCOFTAC/IAHR/QNET-CFD Workshop on Refined Turbulence Modelling, 2002.

29. Guilmineau, E., Deng, G.B., Leroyer, A., Queutey, P., Visonneau, M. and Wackers, J., “Assessment of Hybrid RANSLES Formulations for Flow Simulation Around the Ahmed Body”, Computers and Fluids, 2017. doi:10.1016/j.compfluid.2017.05.005.

30. Krajnovic, S. and Davidson, L., "Flow Around a Simplified Car, Part 2: Understanding the Flow", Journal of Fluids Engineering, 127(5):919-928, 2005, doi:10.1115/1.1989372.

31. Sim-Williams, D.B. and Dominy R.G., "Experimental investigation into unsteadiness and instability in passenger car aerodynamics”, SAE Techincal Paper 980391, 1998, doi: $10.4271 / 980391$.

32. Tacker, A., “Contribution expérimentale à l'analyse stationnaire et instationnaire de l'écoulement à l'arrière d'un corps de faible allongement”, PhD Thesis, Université d’Orléans, 2010.

33. Strachan, R.K., Knowles, K. and Lawson, N.J., "The Vortex Structure behind an Ahmed Reference Model in the Presence of a Moving Ground Plane”, Experiments in Fluids, 42(5):659-669, 2007, doi:10.1007/s00348-007-0270-x.

\section{Contact Information}

Emmanuel Guilmineau

LHEEA, CNRS UMR 6598

Centrale Nantes

1 rue de la Noë, BP 92101

44321 Nantes Cedex 3, France

Emmanuel.Guilmineau@ec-nantes.fr

\section{Acknowledgments}

This work was granted access to the HPC resources of CINES/IDRIS under the allocation A0022A00129 made by GENCI. 